\title{
The Comparison between Two Sternum Closure Techniques after Coronary Bypass Surgery; Sterna-Band $®$ (Peninsula) and Sternum Band (Ethicon®)
}

\author{
Kenan Abdurrahman Kara ${ }^{1 *}$, Zafer Erk ${ }^{2}$, Aytuğ Koçyiğit ${ }^{3}$, Şenol Gülmen ${ }^{4}$ and Hüseyin Okutan ${ }^{5}$ \\ ${ }^{1}$ Department of cardiovascular surgery, Yeditepe University Hospital, Turkey \\ ${ }^{2}$ Department of cardiovascular surgery, Antalya Research and Tranining Hospital, Turkey \\ ${ }^{3}$ Department of cardiovascular surgery, Tekden Hospital, Turkey \\ ${ }^{4}$ Department of cardiovascular surgery, Süleyman Demirel University Hospital, Turkey \\ ${ }^{5}$ Department of cardiovascular surgery, Medicalpark Hospital, Turkey
}

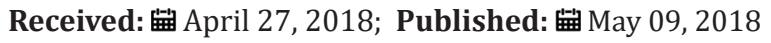

*Corresponding author: Kenan Abdurrahman Kara, Department of cardiovascular surgery, Yeditepe University Hospital, Turkey

\begin{abstract}
Introduction: Recovery failures such as sternal dehiscence, sternal pain, sternal wound infections, osteomyelit and mediastinit can be seen after median sternotomy in coroner bypass surgery. In this study, two sternum band closure methods which we find more effective and secure than conventional sternal closure method are compared.
\end{abstract}

Method: In this prospective study that compares two sternal band closure techniques, 114 patients are divided in two groups as Group A ( $\mathrm{n}=54)$ and Group B ( $\mathrm{n}=60)$. This research compares the results for sternal dehiscence, sternal wound infections, sternal pain and mediastinit in these patient groups between December 2011 and July 2012.

Results: Out of the two, a meaningful recovery is achieved in Group A compared to Group B ( $<<0.05$ ). No superficial woud infection, sternal dehiscence and mediastinit are found in patients of both band groups.

Conclusion: In this study, two different band closure techniques for sternotomy closure after the coroner bypass surgery are compared, and it is revealed that sternal pain index decreases meaningfully, compared to the other.

Keywords: Sternal band; Sternal dehiscence; Sternotomy; Pain index

\section{Introduction}

Median sternotomy is the most frequently used incision for cardiac surgery. Following cardiac surgery by median sternotomy, the sternum is closed by surgical steel wires. Potential postoperative sternal instability definition is dehiscence of sternal parts due to cutting of sternal cortical layers by sternum closing wires with usually inappropriate movements of patient. This may result ranging from increased postoperative pain to sternal wound infection and mediastinitis associated with higher morbidity and mortality and prolonged hospital stay and increased treatment costs [1-4]. Sternal bands used in our study are reported to prevent cutting of sternal cortex as tension on sternum is applied on larger and more balanced area, unlike to conventional sternal steel wires
[4-6]. The aim of this study is to compare two different sternal band closing methods.

\section{Patients and Method}

In our clinic, 114 patients (60 males, 54 females; mean age 65,095 years) underwent to open cardiac surgery between December 2011 and July -2012 were prospectively reviewed (Figure 1). Sternal closing was performed by Peninsula Sterna -Band $\AA$ (L.L.C. Livonia MI. USA) in 54 patients consisting first group (group A) and by Ethicon Sternum Band (Norderstedt, Germany) used in 60 patients consisting second group (group B). Patients with preoperative renal insufficiency, left ventricle dysfunction, receiving anticoagulants, those who have hemorrhagic disorders were not 
included to the study. Preoperative demographic characteristics of patients are shown in Table 1. After cardiac surgery for closing sternum, in group A; two sternal bands were placed at inter costal spaces 3 and 4 . Secondly standard 5/0 steel wires at inter costal spaces 1- 2- 5 and 6 were placed. In Group B, retrosternal sternal band at intercostals spaces 3 and 4 were placed and standard 5/0 steel wires at intercostals spaces 1- 2- 4-5 and 6 were placed.

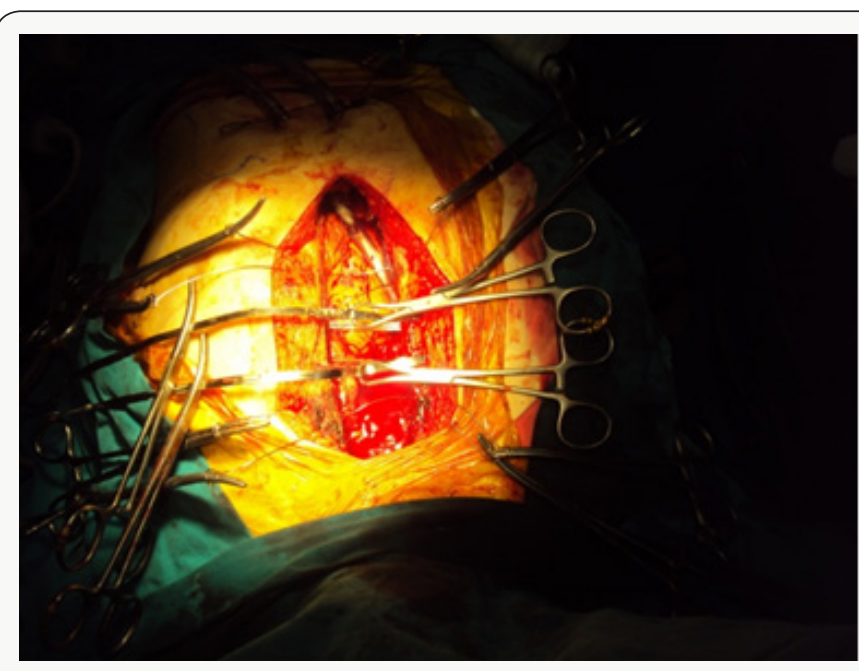

Figure 1:

Table 1: Preoperative demographic characteristics.

\begin{tabular}{|c|c|c|c|}
\hline Group & A & B & p value \\
\hline Patient number & 54 & 60 & NS \\
\hline Age (Years) & $64.96 \pm 9.88$ & $65.23 \pm 10.11$ & NS \\
\hline Weight $(\mathrm{kg})$ & $75.16 \pm 12$ & $78.1 \pm 17.48$ & NS \\
\hline Height $(\mathrm{cm})$ & $165.00 \pm 8.4$ & $166.45 \pm 9.25$ & NS \\
\hline BMI: & $27.59 \pm 3.98$ & $28.12 \pm 5.35$ & NS \\
\hline COPD & $21(\% 38.9)$ & $28(\% 46.7)$ & NS \\
\hline DM & $20(\% 37.0)$ & $27(\% 45)$ & NS \\
\hline Obesity (BMI > 30) & $25(\% 46.3)$ & $23(\% 38.3)$ & NS \\
\hline Osteoporosis & $3(\% 5.6)$ & $9(\% 15)$ & NS \\
\hline Smaller Sternum & $7(\% 13)$ & $6(\% 10)$ & NS \\
\hline
\end{tabular}

COPD: Chronic obstructive pulmonary disease; DM: Diabetes mellitus; BMI: Body mass index; NS: Non-significant.

Then subcutaneous and cutaneous tissues were closed standardly. Following post-operative hemodynamic stability, all patients were ex-tube at hour 4 to 6 and pain index scoring was obtained following mobilization during post-operative intensive care unit. Pain index was obtained by using pain scoring method Visual Analogue Scale (VAS) to evaluate the effect of both bands on post-operative pain. Patients were verbally asked to rate the presence, frequency and severity of pain on the sternum by a scale of 1 to 10. Pain index scoring was calculated by multiplying post-operative pain frequency by pain severity. Statistical analysis was performed by SPSS 15.0 version for Windows (SPSS Inc., Chicago, Illınois, USA) software. T-Test, Pearson Chi-Square test and Mann-Whitney test were used for data analysis (Figure 2).
Statistical data was expressed as mean \pm standard deviation and significance was considered as $\mathrm{p}<0.05$. The study was approved by Süleyman Demirel University Faculty of Medicine Scientific Study Projects Consulting Coordinating Board by project number B.30.2.SDU.0.20.05.07-507/5077 on 27.12.2011 and board decision no. $27 / 6$.

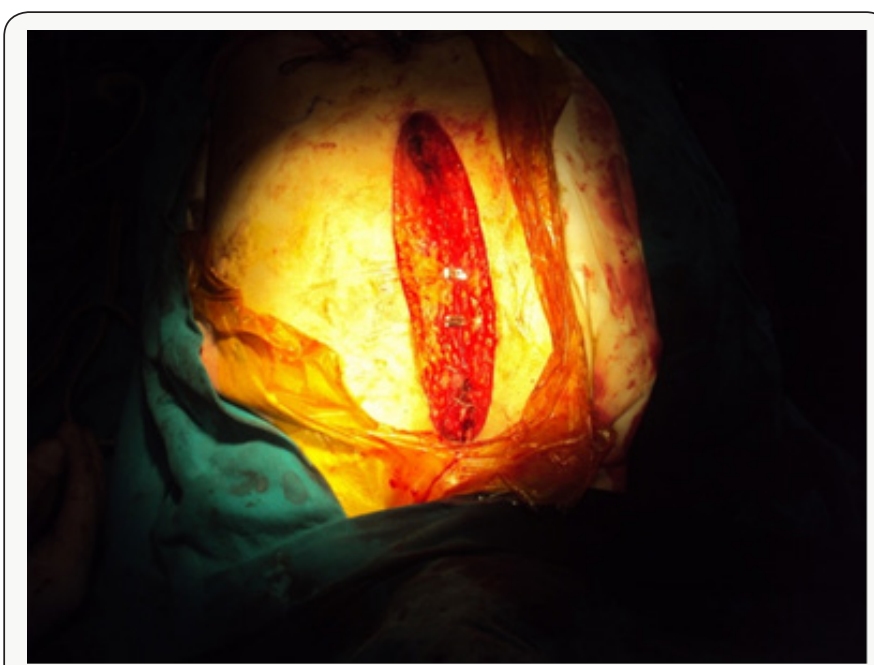

Figure 2:

\section{Results}

Table 2.

\begin{tabular}{|c|c|c|}
\hline & Group A & Group B \\
\hline On pump CABG & 45 & 52 \\
\hline Valve + CABG & 3 & 2 \\
\hline Off-pump CABG & 6 & 3 \\
\hline
\end{tabular}

CABG: Coronary arteries bypass graft

Table 3 .

\begin{tabular}{|c|c|c|c|}
\hline & $\begin{array}{c}\text { Group A } \\
(n=54)\end{array}$ & $\begin{array}{l}\text { Group B } \\
(n=60)\end{array}$ & $\mathbf{P}$ \\
\hline $\mathrm{CPB}$ & $100.1 \pm 26$ & $103.5 \pm 30.2$ & NS \\
\hline ACC & $60.8 \pm 10.2$ & $63.6 \pm 7.0$ & NS \\
\hline Total drain (ml) & $850 \pm 330.5$ & $800 \pm 310.2$ & NS \\
\hline $\begin{array}{l}\text { Drain removal } \\
\text { (hour) }\end{array}$ & $44 \pm 4.1$ & $43 \pm 4.08$ & NS \\
\hline $\begin{array}{c}\text { Superficial } \\
\text { wound infection }\end{array}$ & - & - & - \\
\hline Mediastinitis & - & - & - \\
\hline Dehiscence & 2 & 1 & NS \\
\hline $\begin{array}{c}\text { Discharge time } \\
\text { (days) }\end{array}$ & 7 & 7 & NS \\
\hline Pain index & 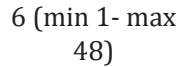 & $\begin{array}{c}4.00(\min .1- \\
\max 63)\end{array}$ & $\begin{aligned} \mathrm{p}= & 0.011, \mathrm{P} \\
& <0.05\end{aligned}$ \\
\hline
\end{tabular}

Pain index: Pain severity $x$ Pain frequency

Pre-operative demographics were not statistically significantly different between two groups (Table 1). Surgery type of operated patients is shown on Table 2 . When peri- and post-operative 
variables were evaluated, there was no statistical difference in respect of cardiopulmonary bypass time (CPB), aortic cross clamp time (ACC), post-operative drainage, the amount of blood utilized, administration of inotropes, drain removal time, superficial wound infection, mediastinitis, dehiscence and hospital discharge day ( p>0.05), (Table 3).

\section{Discussion}

Complete closing of sternum following median sternotomy during open cardiac surgery, is a critical point in prevention of postoperative complications due to sternotomy. These complications include mainly dehiscence as well as a broad range of conditions such as pain, superficial wound infection and mediastinitis. Currently several sternal closing methods were described to prevent these complications [4]. Therefore, in our study we compared two different sternal bands used for sternal closing. In patients with sternotomy, sternal dehiscence is the most frequent complication and the rate is $0.3 \%$ to $5 \%$. This is a mechanical problem associated with certain factors such as lack of attention of patient to protect the sternum post-operatively, COPD, obesity, osteoporosis, use of bilateral mammarian arteries, renal insufficiency, administration of steroids and re-operation [4]. The incidence of sternal wound infection is $0.4-5 \%$ and it is closely associated with dehiscence. Closing of sternum is an important factor for sternal dehiscence. During sternal closing done by conventional approach using steel wires $5 / 0$ or $6 / 0$, bone cortex erosion, fracture and consequently sternal dehiscence can occur due to compression of steel wires. Sternal dehiscence may lead to respiratory dysfunction, infection, increased pain and re-exploration (Figure 3).

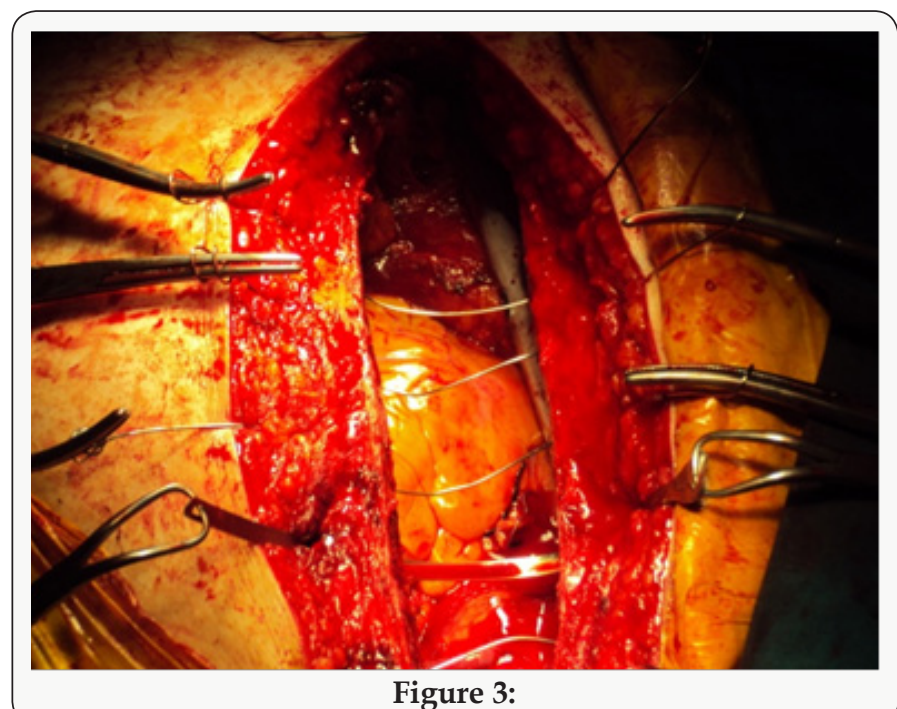

Use of sternal band, especially retrosternal application at intercostals space 3 and 4 to transversely surrounding whole sternum, is the most important mechanism to reduce development of sternal dehiscence with its 6 times larger surface than steel wires and thus providing equal loading on sternum. In our study, sternal dehiscence and sternal wound infection were not detected in both groups. Postoperative pain is an acute pain gradually reducing by tissue healing accompanied also by inflammatory process [6]. Indeed, acute pain is a complex sensation besides its simple perceptional character. Difference in pain perception may be due to central process, fear, anxiety, depression and previous experience on pain perception. Certain patients may not describe the pain due to their higher pain tolerance or their introvert pain handling methods. Difference in pain perception of patients may be also due to post-operative analgesic administration methods. However, $30 \%$ of surgery patients don't require postoperative analgesics [7]. In a prospective clinical study, localization, distribution and severity of postoperative pain were evaluated in consecutive 200 patients with cardiac surgery by median sternotomy [8]. Investigators determined the highest pain intensity on day 1 and lowest intensity on day 3. Although pain distribution was not different during post-operative period, there was difference in its localization [9]. Another factor affecting the pain severity is the age of patient. Young patients reported more severe pain than patients over 60 years (Figure 4).

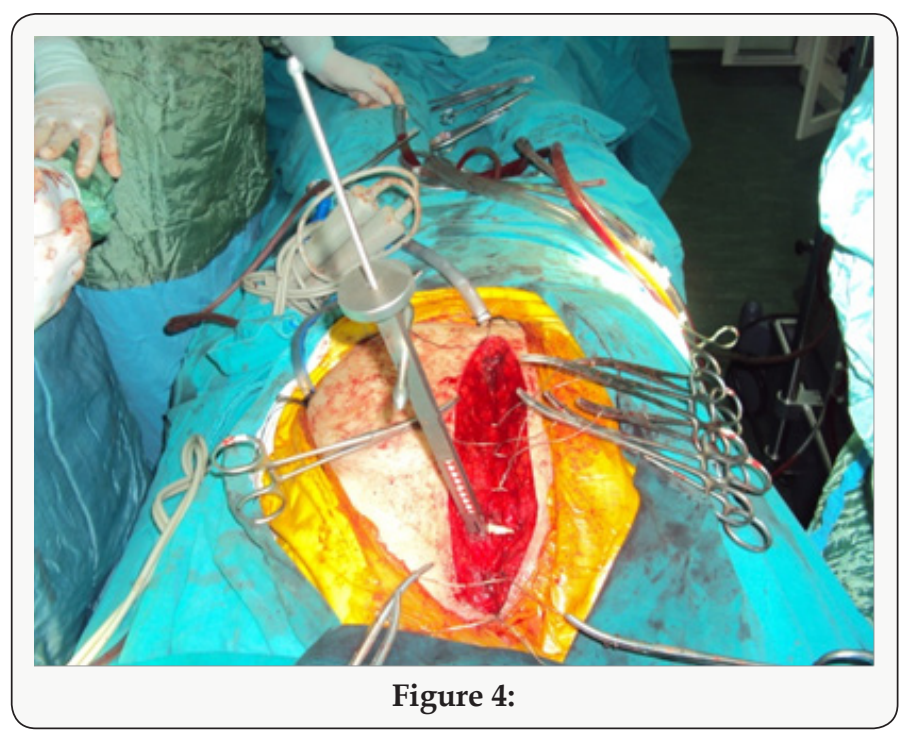

Previous studies comparing sternal band and conventional sternal closing also showed that usage of sternal band was associated with decreased pain and this was explained by reduced development of sternal dehiscence [10-12]. However, in our study, we determined a difference between different methods of sternal bands in respect of pain development. When two groups of our study were compared, there was significant reduction in postoperative pain development in Group B compared to Group A [13]. At this point, we consider that reduced compression of band method on a smaller bone cortex area only at intercostals space 3 in Group B compared to band method of Group A, could explain lower pain. However, we think that the limited number of studies on pain in cardiac surgery and multi factorial nature of pain are limitations of our study [14-16]. Although our study is prospective and including low number of patients, we conclude that larger studies will provide more guidance by including psychological and anatomic-physical parameters such as difference in physical load on bone structure by the material utilized. 


\section{References}

1. A Rahman, O Burma (2001) The effect of coronary artery bypass grafting with Cardiopulmonary bypass and beating heart technique on cardiac performance. Turkish J Thorac Cardiovasc Surg 9: 68-73.

2. H Ekin, V Kutay (2004) Comparison of Cardiac and Cardiopulmonary Bypass Myocardial Revascularizations in Single and Two Vascular Patients. Van Medicine Journal 11(3): 92-97.

3. Cameron A, Davis KB, Green G, Schaff HV (1996) Coronary bypass surgery with internal-thoracic-artery grafts-effects on survival over a 15-year period. N Engl J Med 334(4): 216-219.

4. Friedrich Christian Riess, Nizar Awwad, Bettina Hoffmann (2004) A Steel Band in Addition to 8 Wire Cerclages Reduces the Risk of Sternal Dehiscence after Median Sternotomy. The Heart Surgery Forum 7(6): 387-392.

5. Wewers ME, Lowe NK (1990) A critical review of visual analogue scales in the measurement of clinical phenomena. Research in Nursing \& Health 13(4): 227-236

6. Uyar M (2004) Assessment of postoperative painful patient and measurement of pain. Yücel e ed Postoperative analgesia ( $1^{\text {st }}$ edn.) Istanbul: Mavimer Matbacılık Yayıncılık Ltd Şti pp. 27-36.

7. Rawal N (2000) Psychological Effects of Postoperative Pain Editor: Erdine S Ağrl. Nobel Medical Bookstores 1 Printing pp. 124-125.
8. Mueller XM, Tinguely F, Tevaearai HT (2000) Pain location, distribution and intensity after cardiac surgery. Chest 118(2): 391-396.

9. Moore R, Follette DM, Berkoff HA (1994) Poststernotomy fractures and pain management in open cardiac surgery. Chest 106(5): 1339-1342.

10. Blanchard A, Hurni M, Ruchat P (1995) Incidence of deep and superficial sternal infection after open heart surgery: A ten years retrospective study from 1981 to 1991. Eur J Cardiothorac Surg 9(3): 153-158.

11. Farinas MC, Peralta FG, Bernal JM (1995) Supurative mediastinitis after open heart surgery: A case-control study covering a seven year period in Santander Spain. Clin Infect Dis 20(2): 272-276.

12. He GW, Ryan WH, Acuff TE (1994) Risk factors for operative mortality and sternal wound infection in bilateral internal mammary artery grafting. J Thorac Cardiovasc Surg 107(1): 196199.

13. Kluytmans JAJW, Mouton JW, Ijzermann EPF (1995) Nasal carriage of staphylococcus aureus as a major risk factor for wound infections after cardiac surgery. J Infect Disc 171(1): 216-219.

14. Jurkiewicz MJ, Bostwick J, Hester TR, Bishop JB, Craver J (1980) Infected median sternotomy wound. Ann Surg 191(6): 738-743.

15. Catarino PA, Chamberlain MH, Wright NC, Black E (2000) High-Pressure suction drainage via a polyurethane foam in the management of poststernotomy mediastinitis. Ann Thorac Surg 70(5): 1891-1895.

16. Robiscek F, Fokin A, Cook J, Bhatia D (2000) Sternal Instability after Midline Sternotomy. Thorac Cardiov Surg 48(4): 1-8.

\section{(c) (1) \\ This work is licensed under Creative Commons Attribution 4.0 License}

To Submit Your Article Click Here:

DOI: 10.32474/ACR.2018.01.000106

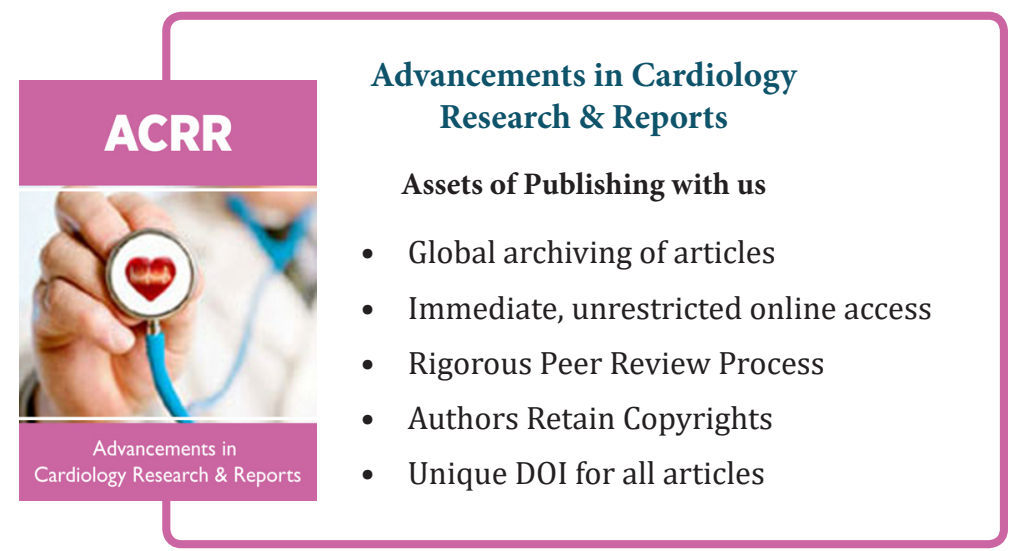

